\title{
UMA PROPOSTA PARA O ENSINO DE LABORATÓRIO DE QUÍMICA ANALÍTICA QUALITATIVA
}

\author{
Julia Pereira Postigo ${ }^{a}$, Hellen Franciane Gonçalves Barbosaa,\#, Roberta Maura Calefia,\#\#, Jany Hellen Ferreira de Jesus ${ }^{\text {a }}$, \\ Priscila Cervini $^{\text {, }}$, Rafael Martos Buoro ${ }^{a}$, Rosa Lucia Simencio Otero ${ }^{a}$ e Éder Tadeu Gomes Cavalheiro ${ }^{\text {a,*, }}$, (1) \\ anstituto de Química de São Carlos, Universidade de São Paulo, 13566-590 São Carlos - SP, Brasil
}

Recebido em 14/09/2020; aceito em 19/10/2020; publicado na web em 18/11/2020

\begin{abstract}
A PROPOSITION FOR TEACHING LABORATORY OF QUALITATIVE ANALYTICAL CHEMISTRY. Teaching laboratory of qualitative analytical chemistry is still a controversial issue in chemistry courses. However, important researchers and educators in chemistry recognized and highlighted the importance that the contents of this discipline represent in the formation of chemists, once it can provide handling and understanding of microscopic phenomena based on the observation of their macroscopic effects, once such reactions and phenomena are the basis of important instrumental methods of analysis. Thus, a proposal based on a bottom-up approach has been developed, starting with the observation of different reactions of cations in laboratory, followed by a search for the reaction responsible for each resulting phenomenon observed during the experimental step. Then these reactions are related with the separation procedures of each group of cations. Eventually the separation of these groups can also be performed depending on the time available. The proposal has been applied in teaching laboratory of qualitative analytical chemistry at Instituto de Química de São Carlos/USP since 2015, where the discipline is offered duirng 4 hours/week, and a positive feedback regarding the evolution of the methodology and its acceptance by students. Good results were also obtained concerning the appropriation of the contents by the students, using the proposal.
\end{abstract}

Keywords: teaching of analytical chemistry; laboratory of qualitative analytical chemistry; macroscopic phenomena; cations separation and identification.

\section{CONSIDERAÇÕES SOBRE O ENSINO DE TEORIA E PRÁTICA DA QUÍMICA ANALÍTICA QUALITATIVA}

A disciplina Química Analítica Qualitativa, especialmente na modalidade experimental clássica, é alvo de grande controvérsia nos cursos de Química em todo o Brasil. Ainda que muitos colegas a considerem fundamental para a formação do futuro profissional, há os que a tenham como uma disciplina ultrapassada e sem utilidade.

Muitos cursos se aproveitaram da Lei de Diretrizes e Bases da Educação (LDB 9394/96), ${ }^{1}$ que previa a flexibilização curricular, para reduzir de forma drástica a carga horária dedicada à essa disciplina, ou mesmo removê-las de suas grades curriculares. ${ }^{2}$

Tradicionalmente, o estudo da Química se divide em cinco grandes áreas: Química Inorgânica, Química Orgânica, FísicoQuímica, Bioquímica e Química Analítica.

A Química Analítica se divide em Clássica e Instrumental. A Química Analítica Clássica envolve a Química Analítica Qualitativa e Química Analítica Quantitativa. A primeira se dedica à identificação dos componentes presentes em uma dada amostra, enquanto a segunda se ocupa da determinação da quantidade de cada componente presente.

De forma geral, o conteúdo teórico do ensino de Química Analítica Qualitativa se baseia na apresentação de fundamentos do equilíbrio químico envolvendo reações ácido-base, de precipitação, de complexação e de óxido-redução.

O conteúdo experimental faz uso de diversas estratégias para a separação de cátions e ânions, usando reações características de

*e-mail: cavalheiro@iqsc.usp.br

${ }^{\dagger}$ Em homenagem ao Prof. Dr. Gilberto Orivaldo Chierice (28/12/1943 19/07/2019, in memoriam), Prof. Titular do IQSC/USP, onde foi responsável por essa disciplina desde 1976 até sua aposentadoria em 2013.

"Endereço atual: Faculdade de Filosofia, Ciências e Letras de Ribeirão Preto, Universidade de São Paulo, 14040-901 Ribeirão Preto - SP, Brasil

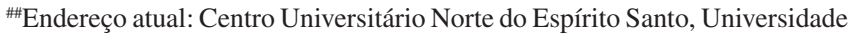
Federal do Espírito Santo, (UFES), 29932-540 São Mateus - ES, Brasil grupos destas entidades químicas, com base em suas reações com determinados reagentes, gerando precipitados, que permitem separar os grupos na fase sólida.

Após isolamento desses grupos, os íons são submetidos a processos de separação que envolvem reações químicas específicas, as quais geram produtos na fase sólida, líquida, ou gasosa, cujas cores, ou outras propriedades sensoriais como o odor, sejam características de um dado cátion ou ânion que se queira identificar. Tais procedimentos são baseados em reações que envolvem processos de precipitação, formação de complexos e óxido-redução, cuja fundamentação é apresentada na parte teórica da disciplina.

Nesse ponto há também forte controvérsia em relação ao uso do gás sulfídrico como reagente de separação dos cátions normalmente analisados e várias propostas tentando a sua substituição vêm sendo feitas há mais de um século. ${ }^{2}$

Com o avanço progressivo da instrumentação analítica, iniciado na década de 1940 e acelerado nas décadas de 1950 e 1960 associados ao avanço da eletrônica, a pesquisa em análise qualitativa passou a despertar um interesse cada vez menor, praticamente não existindo nos dias atuais. ${ }^{3,4}$

Recentemente, houve um significativo desenvolvimento da instrumentação analítica que assumiu uma progressão exponencial, com o advento dos dispositivos de estado sólido (transistores), o surgimento dos microchips, que permitiu (e ainda permite), um desenvolvimento muito veloz dos equipamentos e sua consequente miniaturização. Some-se a isso o avanço da ciência da informação que popularizou os microcomputadores e seus softwares de controle e aquisição de dados.

Essas transformações foram descritas por Alvim e de-Andrade, ${ }^{5}$ que apontam para o fato de que desde os anos 1950-1960, as publicações em Química Analítica Qualitativa passaram a ser voltadas quase que exclusivamente para o ensino, o que pode ser facilmente comprovado pelos vários artigos publicados no Journal of Chemical Education, por exemplo. ${ }^{2}$ 
Simultaneamente, várias universidades americanas passaram a abolir os cursos de Análise Qualitativa e inseri-los como apêndices dos cursos de Análise Instrumental, ao mesmo tempo em que eram descartados os cursos específicos sobre equilíbrio químico, com consequente redução das horas de aulas práticas envolvendo as reações de identificação de cátions e ânions. Esses conteúdos eram eventualmente apresentados nas aulas de Química Geral, ${ }^{6}$ pois acreditava-se que os conteúdos clássicos estavam se tornando técnicos e poderiam ser executados sem treinamento específico.

Nesse contexto, Strong ${ }^{7}$ propôs um curso de Química Analítica Qualitativa, no qual os princípios básicos das técnicas instrumentais deveriam ser apresentados em atividades práticas. Enquanto isso Freiser ${ }^{8}$ propôs uma metodologia voltada apenas à separação e não à detecção de íons.

Entretanto, essas mudanças não resultaram em benefícios ao ensino e chamaram a atenção de muitos educadores altamente reconhecidos, que se mostraram contrários a essas alterações. É muito conhecida a declaração do Dr. Henry Taube, agraciado com o Prêmio Nobel de Química de 1983, que, durante uma entrevista a Rudy M. Baum, ${ }^{9}$ afirmou:

\section{“...o desaparecimento da Análise Qualitativa foi um erro, pois essa constituía um meio de introduzir a química descritiva e de motivar os alunos a estudarem as reações químicas que, "são o coração da química..." (tradução dos autores) ${ }^{8}$}

Essa afirmação motivou muita polêmica quando de sua publicação e trouxe fôlego à discussão sobre a necessidade de manter a Química Analítica Qualitativa nos cursos de Química, servindo de encorajamento aos seus defensores no exterior e no Brasil.

Assim, Benedetti-Pichler et al. ${ }^{10}$ apontaram para a capacidade da Química Analítica Qualitativa em desenvolver no aluno o caráter de pesquisador, já que o ato de desvendar o conteúdo de amostras desconhecidas requer uma abordagem semelhante à usada em pesquisa.

Frank ${ }^{11}$ corroborou essa ideia e a completou ressaltando que a sequência pensar e agir aguça o sentimento de busca e descoberta do futuro pesquisador. Segundo ele, o processo analítico consiste em uma sequência de observação, interpretação, confirmação e conclusão. Essa sequência é a guia do pesquisador nas diversas áreas e, obviamente, nos estudantes de análise qualitativa.

Essa discussão e descontentamento apontaram para a necessidade de reintroduzir a Química Analítica Qualitativa nas grades curriculares de cursos superiores de química, porém de uma forma mais moderna, mas que não levasse à perda de seus aspectos positivos na formação do profissional de química, o que vem se tornando um desafio, desde então.

Como consequência, as universidades americanas e europeias retomaram a Química Analítica Qualitativa inserida em outras disciplinas, especialmente em química geral, nem sempre com disciplinas específicas para esses conteúdos.

No Brasil, um dos principais defensores da disciplina foi o saudoso Prof. Dr. Paschoal Ernesto Américo Senise, ${ }^{12,13}$ do Instituto de Química da USP, um dos primeiros discípulos do Prof. Heinrich Rheinboldt. Em um trabalho publicado em Química Nova, ${ }^{14}$ ele destacou a relevância da Química Analítica Qualitativa na formação do profissional de química, com base na função pedagógica da disciplina, no sentido de estimular o aluno a pensar e raciocinar de forma criativa. ${ }^{12}$ No artigo, ainda se discutem as divergências em relação ao momento mais apropriado e à extensão que a disciplina deveria ocupar nas grades curriculares.

Em seu ensaio, Senise também lembra o alerta de Kolthoff, ${ }^{15}$ sobre as sérias consequências da concepção errônea do papel do químico analítico ao superestimar a instrumentação como recurso simples e suficiente por si mesmo. Acentuando que, sem se apoiar em estudos sistemáticos e no conhecimento das propriedades das substâncias, sob aspectos químicos, físicos ou biológicos, a química analítica ficaria relegada a plano secundário e não teria o desenvolvimento científico adequado, em detrimento do progresso da própria química, ou seja

\section{“...o profissional da química deveria dominar os conceitos químicos que regem a análise instrumental..."15}

Senise também comenta da revisão da retirada da disciplina dos cursos de química nos Estados Unidos, pois se notou uma falta de profissionais capazes de resolverem problemas nessa área, ${ }^{14}$ ressaltando que é importante a forma de abordagem e o destaque dado à disciplina durante a graduação, que terá influência para despertar, ou não, o interesse do aluno na escolha de seu caminho futuro.

O Prof. Senise ponderou que o ensino de química pode ser desenvolvido usando-se diferentes metodologias e que, quando bem ensinada (destaque dos autores), ${ }^{14}$ a Química Analítica Clássica pode ter papel relevante nesse processo, sendo principalmente a Química Analítica Qualitativa quem pode desempenhar esse grande papel do ponto de vista pedagógico. O autor lembra que essa disciplina permite que a capacidade de observação e espírito crítico sejam aguçados e recorda que, em 1980, Herbert A. Laitinen, ${ }^{16}$ outro nome de grande expressão no ensino de química, comentou ser uma pena os químicos modernos não avaliarem o potencial do tubo de ensaio, da placa de toque e do microscópio, para respostas rápidas e simples.

Em outro artigo, ${ }^{17}$ o Professor Senise recordou as ponderações de Lars Kryger, ${ }^{18}$ que considerava não haver substituto para a habilidade experimental e para os conhecimentos químicos fundamentais. Assim, seria de importância vital que o Químico Analítico, mesmo no futuro, quando o acesso aos dados for extremamente facilitado pelos bancos de dados e pelas redes de computadores, soubesse avaliar criticamente a qualidade dos resultados e não perdesse o contato com a bancada.

Um dos discípulos do Prof. Senise foi o Prof. Dr. Eduardo F. A. Neves, também entusiasta da disciplina e seu divulgador tanto no IQ/USP, em São Paulo/SP onde fez a carreira docente, quanto no DQ/USFCar, em São Carlos/SP onde, também, foi Professor Titular.

Os docentes do IQ-UNICAMP, Profs. Nivaldo Baccan, Luiz Manoel Aleixo, Edison Stein e Oswaldo Espírito Santo Godinho, (esse último discípulo de Senise), criaram um marco para o ensino de Química Analítica Qualitativa, ao escreverem o livro "Introdução à Semimicroanálise Qualitativa" ${ }^{19}$ que se tornou bastante conhecido e utilizado em cursos de Análise Qualitativa por todo o Brasil e representou uma valiosa contribuição ao ensino de química analítica em uma época em que livros didáticos em língua portuguesa, escritos no Brasil, eram escassos.

A preocupação com o ensino de Química Analítica Qualitativa em nosso país parece ter se intensificado na década de 90, quando se iniciaram discussões mais acaloradas sobre o tema, ainda que com quase 40 anos de atraso em relação aos EUA.

Desde então, os cursos de química têm passado por revisões, buscando sua modernização e adequação à realidade presente, com sistemáticos cortes na carga horária e na forma de apresentação dos conteúdos de Química Analítica Qualitativa.

Nesse contexto, nosso grupo vem trabalhando há anos em uma proposta de apresentação da Química Analítica Qualitativa Experimental, que se mostrasse mais compacta, para ser ministrada em menores intervalos de tempo, sem que perdesse a essência de seu conteúdo, contemplando sua importância, como ressaltou Senise..$^{14,17}$

No Instituto de Química de São Carlos, da Universidade de São Paulo (IQSC/USP), as aulas experimentais são realizadas em 4 horas semanais, no segundo semestre do curso, o que mostrou ser um tempo 
reduzido para a execução dos roteiros convencionais oferecidos, que, basicamente, resumem-se em seguir a marcha analítica de separação de cátions. Dessa forma, esse trabalho propôs modificar a forma de apresentação do conteúdo, para adequá-lo aos tempos atuais.

Nesse trabalho é apresentado o resultado desses esforços e sua aplicação no curso de Bacharelado em Química na disciplina de Química Analítica Qualitativa Experimental, do IQSC/USP e os resultados da avaliação da proposta pelos discentes.

\section{CONSIDERAÇÕES SOBRE A ABORDAGEM PROPOSTA E SUA FILOSOFIA}

A presente abordagem foi construída com o intuito de melhorar a compreensão dos alunos sobre as reações envolvidas na Química Analítica Qualitativa, particularmente no seu aspecto experimental, considerada um dos pilares de formação do profissional da química e tendo em vista que a marcha analítica tradicional passou a ser praticamente impossível de ser utilizada, devido à redução da carga horária destinada à disciplina que, enquanto restringe o tempo de aula, torna o procedimento confuso aos alunos, dificultando os esforços de ensinar, por parte dos instrutores e de aprender, por parte dos discentes, pois há muito conteúdo a apresentar e pouco tempo para assimilação.

A marcha analítica tradicional consiste em uma série de reações e procedimentos sequenciais, que levam à separação dos diferentes cátions em grupos, segundo suas reações em comum, seguida da identificação desses cátions, com base em reações específicas de cada um deles. Quando esse processo é feito sem tempo de assimilação, há uma dificuldade em acompanhar a lógica das sequências a serem realizadas e não se pode dedicar o cuidado necessário ao sucesso das reações envolvidas em cada etapa. Isso leva ao não entendimento do que está sendo feito e insucesso nas reações de separação e identificação, resultando em uma completa perda de tempo e desperdício de recursos.

Além disso, há a frustração por parte dos alunos que não conseguem atingir o objetivo de separar e identificar os cátions presentes nas famosas "amostras desconhecidas". Isso é agravado quando a equipe instrutora não tem preparo e/ou envolvimento com a disciplina, levando quase ao caos. Esse contexto, obviamente, subsidia os argumentos dos opositores da disciplina.

Por outro lado, a disciplina Química Analítica Qualitativa Experimental envolve um conteúdo consolidado e tradicional, o que torna difícil promover adaptações ou mudanças. A seleção de amostras do cotidiano dos alunos como águas, solos, minérios e outras podem atrair a atenção dos alunos, mas não afetam o conteúdo.

Nosso grupo já utilizou como exemplo a "lama de Mariana", por ocasião do evento lamentável ocorrido naquela localidade, como atividade do Programa PAE-USP, ${ }^{20}$ na qual os alunos puderam propor procedimentos para separação de alguns cátions presentes naquela amostra, ao final do semestre. A atividade consistiu em uma preleção teórica, discussão do problema, destaque aos cátions presentes em maior abundância naquela amostra e as suas reações receberam atenção. Finalmente, foi solicitado aos alunos que criassem esquemas de separação, com base no conteúdo da disciplina.

Outro aspecto relevante é o volume de resíduos gerados e sua toxicidade, pois no trabalho experimental são envolvidos reagentes com alta potencialidade tóxica, como os íons de metais a serem analisados, corantes, solventes e o próprio gás sulfídrico, quando utilizado.

Entretanto, a profissão de químico envolve o trabalho e contato com substâncias nem sempre saudáveis, nem ambientalmente amigávei. Uma das principais características da química analítica qualitativa é oferecer de forma cuidadosa e segura, o treinamento e o entendimento de como lidar com essas substâncias na vida prática e no futuro exercício profissional. O Conselho Regional de Química IV Região, lembra que: ${ }^{21}$

Por isso, o químico pode trabalhar não só nos laboratórios, mas em todas as atividades que exigem o acompanhamento de um profissional. Estas atividades envolvem: projeto, planejamento e controle de produção; desenvolvimento de produtos; operações e controle de processos químicos; saneamento básico; tratamento de resíduos industriais; segurança; gestão de meio ambiente e, em alguns casos específicos, vendas, assistência técnica, planejamento industrial e até direção de empresas. Sem dizer que a chamada química forense tem sido uma grande aliada dos investigadores para a solução de crimes. ${ }^{21}$

Assim, não há como se esquivar dessa oportunidade de mostrar ao futuro profissional a forma adequada de lidar com tais substâncias, presentes no meio ambiente, em produtos industrializados de grande importância na sociedade contemporânea e até mesmo em laboratórios forenses.

Por exemplo, o Grupo I de cátions, segundo Vogel, contem $\mathrm{Ag}(\mathrm{I}), \mathrm{Pb}(\mathrm{II})$ e $\mathrm{Hg}(\mathrm{I})$, cujas reações e comportamento químico são demonstrados nessa disciplina. $\mathrm{O} \mathrm{Pb}$ (II) está presente nas baterias chumbo-ácido que são usadas cotidianamente em veículos automotores e está presente como contaminante ambiental, como por exemplo o terreno de uma fábrica de baterias em Bauru/SP. ${ }^{22}$ O mercúrio é usado indiscriminadamente em garimpos ilegais e contamina leitos de águas naturais e solos na região amazônica, mas também tem ampla aplicação industrial, como catalisador. Negligenciar essas informações seria formar um profissional incompleto e não capacitado para o bom uso, a destinação adequada ao final da vida útil e mesmo para a remediação de danos causados por tais elementos. Assim, uma das maiores preocupações dessa proposta também é minimizar a quantidade dessas substâncias usadas durante o curso, sem prejuízo ao aprendizado.

Há também o fator tempo das aulas experimentais, reduzido para 4 horas semanais na maioria dos cursos no Brasil. ${ }^{2}$ Nesse tempo reduzido é preciso apresentar o conteúdo da disciplina e oferecer o curso de forma clara e eficiente para que os alunos possam se apropriar da riquíssima carga conceitual e entender como se dão os processos de separação e identificação, o que lhes pode oferecer oportunidade única de aprendizado como dito acima. ${ }^{4,6,19,23,24}$

Assim, é preciso apresentar um conteúdo extenso e complexo, que envolve geração de resíduos, muitas vezes tóxicos, em volume considerável; em tempo reduzido; que requer uma equipe instrutora que tenha domínio do conteúdo e motivada em relação à disciplina; para alunos ingressantes (muitos deles pouco experientes em laboratório), sem perder o foco na formação sólida dos discentes.

Tendo todos esses fatores em consideração e com a experiência acumulada ao longo de anos ministrando a disciplina, foi proposto um procedimento que possa contemplar todos esses aspectos. Nessa proposta, o comportamento químico individual dos cátions é estudado, segundo suas reações em comum, mas sem necessariamente fazer uso da marcha analítica tradicional.

Após uma preleção sobre as principais características do grupo em estudo, os alunos são convidados a procederem uma série de reações selecionadas para demonstrar tais características. Para isso, a equipe instrutora fornece aos alunos um guia de estudo dirigido, que propõe as reações mais importantes dos cátions de cada grupo, com os diversos reagentes envolvidos nessas reações.

Ao procederem as reações, os alunos anotam os diferentes fenômenos que podem ser observados. Essas reações devem ser 
selecionadas de forma a mostrar as semelhanças e diferenças de comportamento de cada componente do grupo. Um exemplo de reações selecionadas para estudar o comportamento dos cátions do Grupo I, segundo Vogel, ${ }^{23}$ é apresentado na Tabela 1. O Grupo I foi escolhido como exemplo representativo, pois é um grupo com poucos elementos e com reações bastante interessantes e características, além de relativamente fácil de manipular. O mesmo deve ser feito para os demais grupos, na sequência do curso.

Espera-se que o estudante observe que em todas as reações dos cátions do Grupo I com $\mathrm{HCl}$ forma-se um precipitado branco, entretanto esse precipitado se comporta de maneira diferente na presença de outros reagentes, como amônia e tem diferentes solubilidades no aquecimento. Seguem-se reações dos três cátions com $\mathrm{NaOH}, \mathrm{K}_{2} \mathrm{CrO}_{4}$ e KI. Eventualmente, essas reações são seguidas de novas etapas de reação, incluindo adição de excesso do reagente em estudo, adição de outros reagentes, aquecimento, resfriamento etc., para demonstrar as diferenças. As observações esperadas para cada reação e suas etapas seguintes são marcadas em vermelho na Tabela 1.

Terminada essa etapa, os alunos são solicitados a pesquisarem em livros-texto clássicos, como os de Baccan et al.,${ }^{19}$ Vogel, ${ }^{23}$ Brumblay, ${ }^{24}$ entre outros, quais as reações químicas envolvidas e a explicação para os fenômenos observados. Exemplos dos resultados esperados dessas pesquisas aparecem em azul na Tabela 1 .

Terminada essa segunda fase, o aluno deve ser capaz de distinguir as semelhanças e diferenças de comportamento químico dos componentes do grupo, frente aos diferentes reagentes com os quais eles foram postos a reagir.

Sendo ingressantes no curso, geralmente, eles não têm maturidade para propor uma separação de cátions. Então, nesse ponto há dois caminhos. O primeiro é solicitar que eles busquem informação de como proceder a separação dos cátions intragrupos e o segundo é a equipe instrutora apresentar um fluxograma de separação, comum nos livros-texto, como aquele sugerido na Figura 1 e discuti-lo detalhadamente com a turma. Nossa experiência aponta que o segundo

Tabela 1. Exemplo de uma tabela que aborda algumas as reações investigadas durante uma das aulas experimentais, aqui o Grupo I de cátions, segundo Vogel..$^{23}$ Em vermelho estão exemplos das anotações esperadas para as observações e em azul os produtos de reação e comentários explicativos, de cada caso

\begin{tabular}{|c|c|c|c|c|c|c|}
\hline Reação & Reagentes & Observação & Nova etapa & Observação & Nova etapa & Observação \\
\hline \multirow{6}{*}{$\mathrm{HCl}_{\mathrm{dil}}+$} & $\mathrm{Pb}^{2+}$ & precipitado branco & aquecer na capela & dissolve & resfriar & precipita \\
\hline & \multicolumn{2}{|c|}{ Forma-se $\mathrm{PbCl}_{2}$} & \multicolumn{2}{|c|}{ O precipitado é solúvel a quente } & \multicolumn{2}{|c|}{ Forma-se novamente o $\mathrm{PbCl}_{2}$} \\
\hline & $\mathrm{Hg}_{2}^{2+}$ & precipitado branco & aquecer na capela & não dissolve & \multirow{2}{*}{\multicolumn{2}{|c|}{$\begin{array}{c}\mathrm{NH}_{3} \quad \text { precipitado preto } \\
\text { Ocorre o desproporcionamento de } \mathrm{Hg}_{2}{ }^{2+} \\
\text { em } \mathrm{Hg}^{\circ} \text { e } \mathrm{Hg}\left(\mathrm{NH}_{2}\right) \mathrm{Cl}\end{array}$}} \\
\hline & \multicolumn{2}{|c|}{ Forma-se o calomelano, $\mathrm{Hg}_{2} \mathrm{Cl}_{2}$} & & & & \\
\hline & $\mathrm{Ag}^{+}$ & precipitado branco & aquecer na capela & não dissolve & \multirow{2}{*}{\multicolumn{2}{|c|}{$\begin{array}{c}\mathrm{NH}_{3} \text { dissolve } \\
\text { Excesso de } \mathrm{NH}_{3} \text { dissolve o precipitado de } \\
\mathrm{AgCl}, \text { formando diaminprata }\left[\mathrm{Ag}\left(\mathrm{NH}_{3}\right)_{2}\right]^{+}\end{array}$}} \\
\hline & \multicolumn{2}{|c|}{ Forma-se $\mathrm{AgCl}$} & & & & \\
\hline \multirow{6}{*}{$\mathrm{NaOH}+$} & $\mathrm{Pb}^{2+}$ & precipitado branco & + excesso $\mathrm{NaOH}$ & dissolve & & - \\
\hline & \multicolumn{2}{|c|}{ Forma-se $\mathrm{Pb}(\mathrm{OH})_{2}$} & \multicolumn{2}{|c|}{$\begin{array}{l}\text { Dissolve com formação de } \\
\text { tetrahidroxiplumbato, }\left[\mathrm{Pb}(\mathrm{OH})_{4}\right]^{2-}\end{array}$} & & \\
\hline & $\mathrm{Hg}_{2}^{2+}$ & precipitado preto & + excesso $\mathrm{NaOH}$ & nada & & - \\
\hline & \multicolumn{2}{|c|}{ Forma-se $\mathrm{Hg}_{2} \mathrm{O}$} & \multicolumn{2}{|c|}{$\begin{array}{c}\text { Não dissolve em excesso. } \mathrm{Na} \text { ebulição } \\
\text { desproporciona em } \mathrm{HgO} \text { e } \mathrm{Hg}^{\circ}\end{array}$} & & \\
\hline & $\mathrm{Ag}^{+}$ & precipitado marrom & + excesso $\mathrm{NaOH}$ & nada & & - \\
\hline & \multicolumn{2}{|c|}{ Forma-se $\mathrm{Ag}_{2} \mathrm{O}$} & \multicolumn{2}{|c|}{ Insolúvel no excesso de reagente } & & \\
\hline \multirow{6}{*}{$\begin{array}{l}3 \\
\mathrm{~K}_{2} \mathrm{CrO}_{4}+\end{array}$} & $\mathrm{Pb}^{2+}$ & precipitado amarelo & $+\mathrm{NH}_{3}$ & nada & & \\
\hline & \multicolumn{2}{|c|}{ Forma-se $\mathrm{PbCrO}_{4}$} & \multicolumn{2}{|c|}{$\begin{array}{l}\text { Não dissolve. Se dissolveria com } \mathrm{NaOH} \\
\qquad \mathrm{Ou} \mathrm{HNO}_{3}\end{array}$} & & \\
\hline & $\mathrm{Hg}_{2}^{2+}$ & precipitado marrom & aquecer & precipitado vermelho & $+\mathrm{NaOH}$ & precipitado preto \\
\hline & \multicolumn{2}{|c|}{$\begin{array}{c}\text { Forma-se precipitado amorfo e de } \\
\text { composição indefinida }\end{array}$} & \multicolumn{2}{|c|}{ Forma-se $\mathrm{Hg}_{2} \mathrm{CrO}_{4}$ vermelho } & \multicolumn{2}{|c|}{ Forma-se $\mathrm{Hg}_{2} \mathrm{O}$} \\
\hline & $\mathrm{Ag}^{+}$ & precipitado vermelho & $+\mathrm{NH}_{3}$ & dissolve & & - \\
\hline & \multicolumn{2}{|c|}{ Forma-se $\mathrm{Ag}_{2} \mathrm{CrO}_{4}$} & \multicolumn{2}{|c|}{ Forma-se $\left[\mathrm{Ag}\left(\mathrm{NH}_{3}\right)_{2}\right]^{+}$solúvel } & & \\
\hline \multirow{6}{*}{4} & $\mathrm{~Pb}^{2+}$ & precipitado amarelo & ferver e resfriar & cristais amarelos & + excesso KI & dissolve \\
\hline & Forma-se $\mathrm{Pb}$ & & \multicolumn{2}{|c|}{$\begin{array}{c}\text { O PbI se dissolve ao ferver e recristaliza } \\
\text { no resfriamento (chuva de ouro) }\end{array}$} & $\begin{array}{r}\text { Dissol } \\
\text { tetraiodoplu }\end{array}$ & $\begin{array}{l}\text { formando } \\
\text { ato }(\mathrm{II}),\left[\mathrm{PbI}_{4}\right]^{2-}\end{array}$ \\
\hline & $\mathrm{Hg}_{2}{ }^{2+}$ & precipitado verde & + excesso KI & precipitado preto & & \\
\hline & \multicolumn{2}{|c|}{ Forma-se $\mathrm{Hg}_{2} \mathrm{I}_{2}$} & \multicolumn{2}{|c|}{$\begin{array}{c}\text { Ocorre o desproporcionamento de } \mathrm{Hg}_{2}^{2+} \\
\text { em } \mathrm{Hg}^{\circ} \text { e tetraiodomercurato }\left[\mathrm{HgI}_{2}\right]^{2-}\end{array}$} & & \\
\hline & $\mathrm{Ag}^{+}$ & precipitado amarelo & & - & & \\
\hline & \multicolumn{4}{|c|}{ Forma-se AgI } & & \\
\hline
\end{tabular}


caminho é mais producente. Em ambos os casos é importante discutir esse procedimento mostrando como as reações investigadas na etapa anterior podem ser usadas no agrupamento dos cátions, isolando-os dos concomitantes presentes em uma eventual amostra a ser analisada e, posteriormente, separando-os e identificando-os.

Ao final desse processo, espera-se que cada aluno seja capaz de entender que os cátions do grupo em estudo podem ser isolados da amostra inicial, por suas características comuns e, posteriormente, separados e identificados por suas características individuais. Isso representa uma abordagem segundo a qual, a partir da observação dos fenômenos macroscópicos, possa-se entender que há reações químicas de caráter similar e dissimilar envolvendo os cátions de um determinado grupo, o que permite propor sua identificação em uma amostra.

Se houver disponibilidade de tempo, é interessante que os alunos realizem a separação dos cátions do grupo em estudo, a partir de amostras artificiais ou naturais que os contenham, como é feito na modalidade convencional, mas apenas após desenvolverem as atividades descritas acima, desde os testes das reações até a discussão final sobre seus resultados e possiblidade de aplicação.

Portanto, a proposta se baseia em uma abordagem construtivista, na linha da aprendizagem significativa de Ausubel, caracterizada pela observação dos fenômenos envolvendo inicialmente apenas os íons de cada grupo, seguida da organização dos conceitos partindo dessa menor unidade..$^{25,26}$ Assim, eles se tornam conceitos subsunçores para construção de conhecimento e apropriação de novos conceitos, ${ }^{25,26}$ tendo como objetivo final o entendimento dos processos de separação e identificação de íons em um conjunto universal, representado pela amostra, conforme ilustrado no Esquema 1.

Assim, ao final do curso espera-se que os alunos sejam capazes de entender as reações individuais dos cátions de cada grupo e como seria possível usá-las na sua separação e identificação. Essa é a principal meta da proposta. Ao mesmo tempo, ao concluir o conteúdo programático eles devem ser também capazes de entender qual a fundamentação que permite reunir os cátions em grupos e como se poderia separá-los e identificá-los, ainda que não se proceda a marcha analítica completa. Dessa forma, o aluno deve compreender que é a partir do entendimento dos fenômenos que ocorrem nas reações individuais que é possível fazer o exercício inverso e, na prática, faz-se o caminho inverso, partindo-se da amostra para identificar os cátions nela contidos.

\section{DINÂMICA DA PROPOSTA}

Em uma aula inicial os alunos são esclarecidos sobre o histórico da química analítica qualitativa, as críticas que recebe $v s$. sua importância, além da sua inserção na área de química analítica clássica, na química e no contexto científico. ${ }^{2}$ Finalmente, a proposta didática é apresentada, assim como os diferentes processos de classificação dos cátions e a opção, em nosso caso, pela classificação de Vogel. ${ }^{23}$ A turma é convidada a se organizar em duplas, que realizarão as atividades durante o semestre e recebem uma caixa com frascos conta-gotas, os quais devem preencher com todas as soluções que poderão ser usadas durante o curso.

Para desenvolvimento da metodologia proposta, inicialmente uma tabela com as principais reações dos cátions de cada grupo é apresentada aos alunos, que são convidados a realizar essa bateria de testes. Obviamente, o conjunto de reações disponíveis para todos os cátions de cada grupo é grande ${ }^{23} \mathrm{e}$ os instrutores deverão selecionar aquelas mais significativas e importantes para o entendimento do

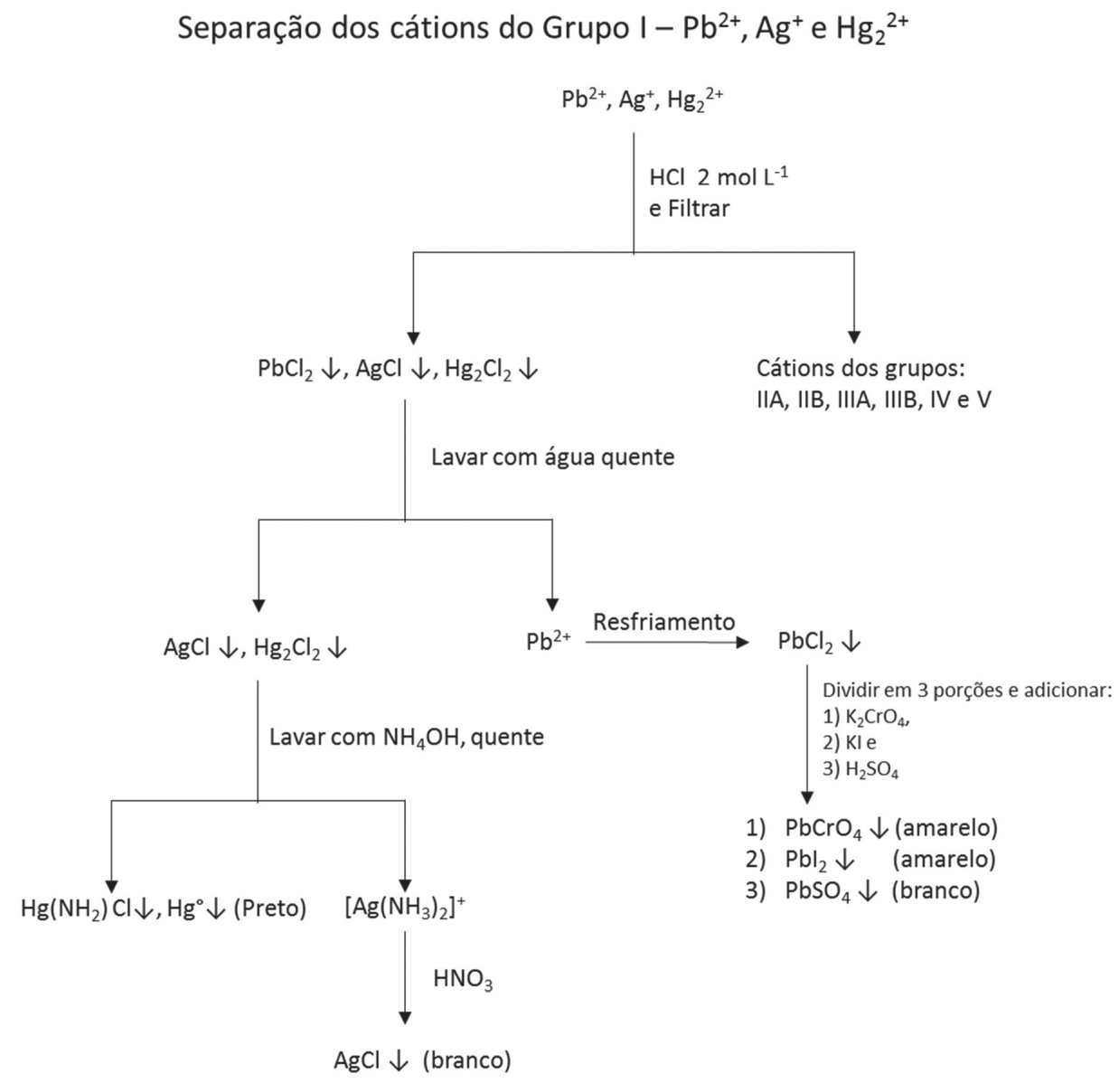

Figura 1. Exemplo de fluxograma das reações dos cátions do Grupo I, segundo Vogel ${ }^{23}$, abordadas em aulas experimentais 


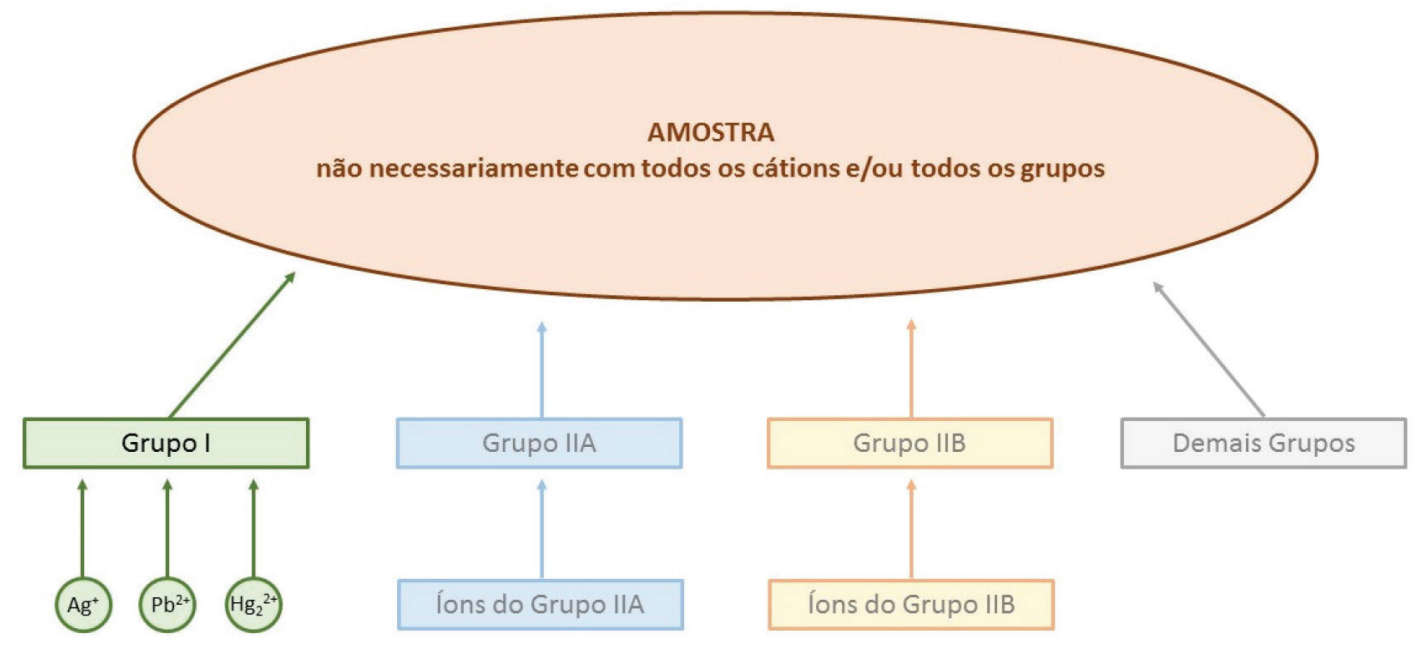

Esquema 1. Representação da aproximação construtivista da proposta, segundo a qual a partir das reaçães dos cátions eles podem ser entendidos como grupos. Esses grupos juntos podem compor a amostra. Entretanto, nem todas as amostras contém todos os grupos ou mesmo todos os cátions. Nesta ilustração destacam-se de forma simplificada apenas os cátions do Grupo I, segundo Vogel, ${ }^{23}$ que foram usados como exemplo no texto e os demais grupos que podem ser estudados em cada etapa do curso

comportamento dos cátions, em relação às suas semelhanças, que permitem agrupá-los e diferenças, que permitem reconhecê-los, usando a(s) referência(s) bibliográfica(s) de sua preferência. Um exemplo representativo é apresentado na Tabela 1 , que contém

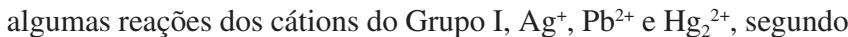
Vogel: ${ }^{23}$ como sugestão.

Os alunos, por sua, vez realizam as reações sugeridas e anotam as observações, sem se preocuparem com as reações ou fenômenos ocorridos nessa fase dos trabalhos. Cada reação teste é realizada adicionando-se 1,0 $\mathrm{mL}$ de água purificada em sistema de osmose reversa a um volume mínimo e suficiente de cada reagente, visando minimizar os resíduos gerados. A principal vantagem de usar a água purificada em sistema de osmose reversa é a economia de energia e água, em relação aos sistemas de destilação tipo Pilsen. A água destilada também pode ser utilizada, não havendo necessidade de uso de água purificada em sistemas de ultrapurificação.

Em uma segunda etapa, os discentes devem procurar em livrostexto ${ }^{6,19,23,24}$ as reações propostas e explicar os fenômenos observados em termos de reações químicas e dos fenômenos macroscópicos observados como sua consequência.

A terceira etapa ocorre após essa compilação, quando a classe se reúne com os instrutores e, a partir das observações e estudos realizados, espera-se que fique claro aos alunos que (novamente usando o Grupo 1 como exemplo):

1. Esses cátions precipitam na presença de $\mathrm{HCl}$ devido à solubilidade relativamente mais baixa dos seus cloretos, o que permitiria isolá-los de uma eventual amostra.

2. Esses cloretos apresentam diferentes comportamentos, o que permitiria isolá-los dentro do grupo.

3. Nesse momento pode-se começar a apresentar a possibilidade de separação, com as observações coletadas em aula e compiladas na literatura.

4. Após isolamento do grupo eles são separados entre si, com uso de água quente, que dissolve o cloreto de chumbo, posteriormente identificado como precipitado branco, após adição de sulfato ou amarelo, pela adição de cromato ou iodeto. A prata(I) e o mercúrio(I) são separados pela adição de solução de amônia aquecida, quando a prata se dissolve formando o complexo diaminprata $\left[\mathrm{Ag}\left(\mathrm{NH}_{3}\right)_{2}\right]^{+}$, que deve ser coletado e acidificado com ácido nítrico regenerando o $\mathrm{AgCl}$. O mercúrio retido no filtro se desproporciona, produzindo $\mathrm{Hg}^{\circ}$ (sólido preto, finamente dividi- do) e se oxidando com formação de amidocloreto de mercúrio(II), $\mathrm{Hg}\left(\mathrm{NH}_{2}\right) \mathrm{Cl}$, branco.

5. Se conduzida adequadamente, essa discussão pode levar aos famosos fluxogramas de separação dos grupos, como aquele apresentado na Figura 1, para o Grupo I.

6. Havendo tempo, os alunos podem ser convidados a realizar a separação dos cátions do grupo em estudo, usando esse fluxograma.

Ao final da rodada de estudos de cada grupo os alunos devem apresentar um relatório, com a descrição das observações e as reações envolvidas, pesquisadas nos livros texto e os resultados da separação dos cátions em amostras desconhecidas, usando o fluxograma que eles tenham elaborado, se realizada.

Técnicas de filtração, evaporação, testes de chama e todas as demais operações envolvidas nestes procedimentos são e demostradas aos alunos, buscando exigir deles o máximo rigor nos procedimentos para treiná-los no uso da instrumentação e, também, visando sua segurança. Assim, além da enorme carga conceitual, as aulas de laboratório de Química Analítica Qualitativa permitem, ainda, apresentar os cuidados experimentais envolvidos no trabalho prático do químico.

Nós temos dividido o curso em dois blocos: $\mathrm{O}$ Bloco 1 com os Grupos I, IIA e IIB e o Bloco 2 com os Grupos IIIA, IIIB, IV e V, como representado no Esquema 2. Ao final do estudo de cada um dos blocos os alunos recebem uma amostra desconhecida contendo cátions dos grupos de cada bloco e devem identificá-los, em uma prova prática. Cada equipe instrutora deverá adequar essas atividades ao tempo disponível em suas respectivas Instituições, ao usar a proposta.

Em nosso caso, ao final do semestre, todos os resíduos gerados são recolhidos e enviados ao setor responsável pelo tratamento de resíduos do Campus de São Carlos da USP, seguindo as normas e procedimentos daquele setor. ${ }^{27}$

Como avaliação da proposta, enquanto instrutores, pode-se afirmar que, em relação ao método tradicional, notaram-se as seguintes vantagens: (1) os alunos ficam mais interessados em esclarecer o que houve em cada reação realizada, mostrando motivação; (2) A observação seguida da pesquisa da reação desenvolve habilidade de resolver problemas e induz independência; (3) demonstra a possiblidade de buscar as referências bibliográficas existentes, como fontes confiáveis de informação; (4) há significativa redução nos volumes de resíduos.

Após seis anos de aplicação dessa proposta, em paralelo com turmas que seguem o padrão tradicional, nas quais os alunos são introduzidos diretamente na separação dos grupos e cátions pela 

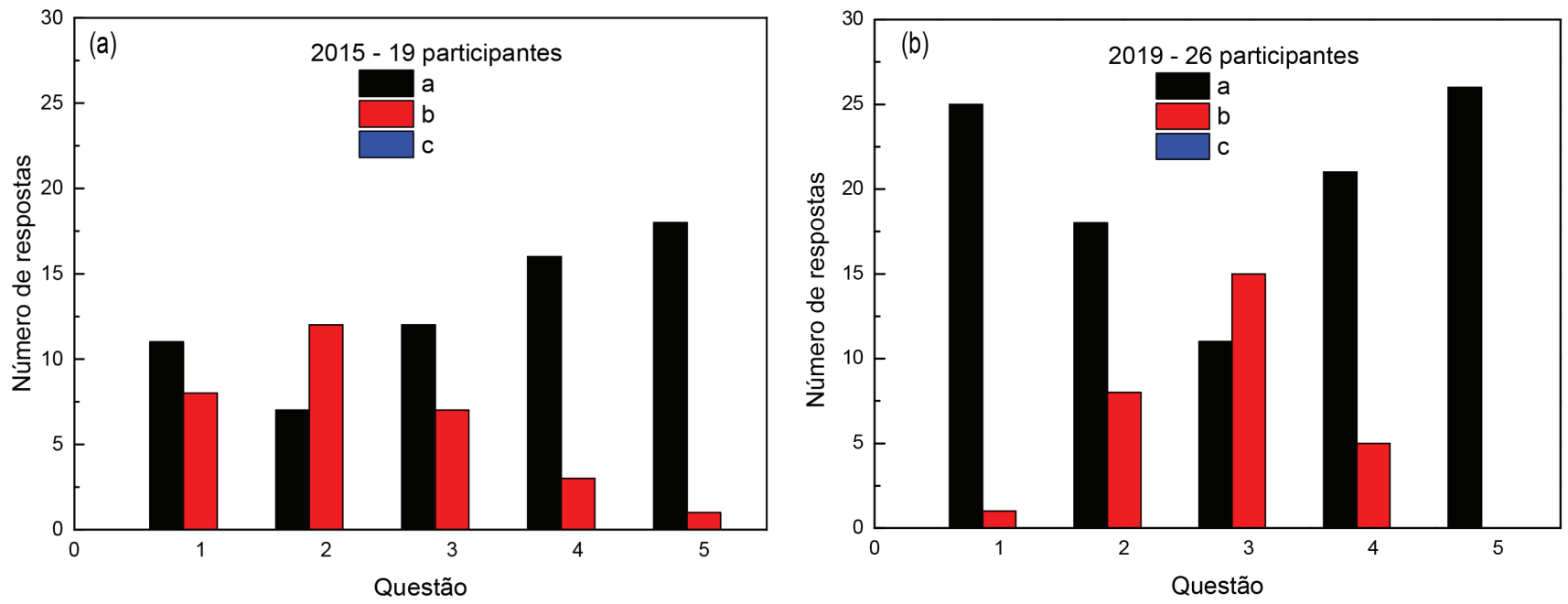

Figura 2. Respostas dos alunos ao questionário de avaliação da metodologia proposta (Figura 1S, no Material Suplementar) em (a) 2015 e (b) 2019 . Não houve respostas na alternativa (c, azul) em nenhum dos casos
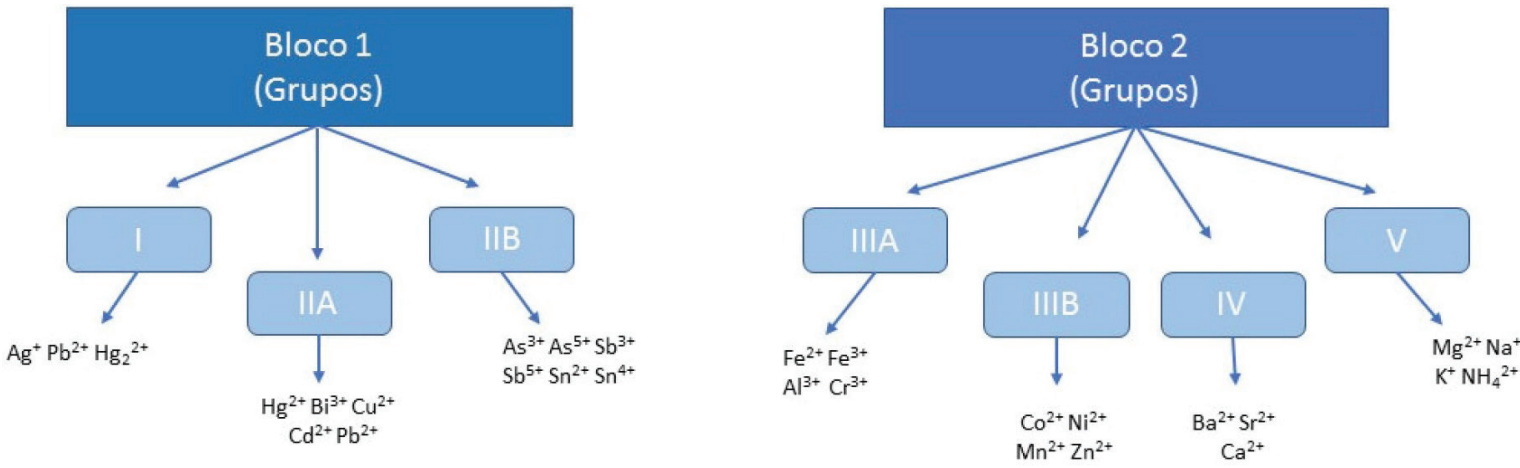

Esquema 2. Sugestão organização dos grupos de cátions em dois blocos, para apresentação do conteúdo

marcha analítica, as vantagens apontadas acima ficam evidentes, ainda que de forma qualitativa.

\section{APLICAÇÃO EM LABORATÓRIO DIDÁTICO}

No Instituto de Química de São Carlos da Universidade de São Paulo (IQSC/USP), a disciplina SQM0408 - Laboratório de Química Analítica Qualitativa ${ }^{28}$ é oferecida de forma semestral, no segundo período regular do curso de bacharelado em química, com carga horária total de 4 horas semanais. Geralmente são formadas 3 turmas de 20 alunos cada. No início o procedimento era aplicado a uma turma, sendo agora utilizado por 2 turmas, enquanto a terceira mantém procedimentos tracionais baseados em apostilas e no livro de Vogel, ${ }^{23}$ por opção da equipe instrutora.

O conteúdo programático envolve: Análise Sistemática de mistura de cátions e ânions. Exame Inicial de Amostras; Precipitação e Identificação de cátions do Grupo I; Precipitação e Identificação de Cátions do grupo II; Precipitação e identificação dos cátions do Grupo III; Precipitação e identificação dos cátions do Grupo IV; Precipitação e identificação dos cátions do Grupo V; Separação e identificação de ânions. ${ }^{28}$ Dessa maneira, a proposta se ajusta ao conteúdo esperado da disciplina.

Neste relato apresentam-se os resultados da aplicação da proposta a uma turma de 20 alunos do curso, dos quais 19 responderam de forma voluntária e sem identificação a um questionário sobre a proposta ao final do curso, como forma de avaliação, quando da sua primeira utilização, no segundo semestre de 2015 e uma nova rodada de avaliação da metodologia aplicada em 2019, após 4 anos de aprimoramento do material usado. Nessa nova rodada a metodologia foi aplicada a 32 alunos divididos em duas turmas, dos quais 26 participaram da avaliação de forma voluntária.

\section{Avaliação da proposta, pelos alunos}

A Figura 2 apresenta os resultados da avaliação da metodologia pelos alunos nas duas oportunidades. As questão são apresentadas na Figura 1S, no Material Suplementar

As respostas revelam uma evolução na aplicação da metodologia. O material foi bem avaliado, tendo melhorado sua aceitação (Questão 1), com aumento nessa opinião ao longo do tempo, certamente pelo aprimoramento do texto e vivência da equipe instrutora na aplicação da proposta. A mesma tendência ocorreu em relação à associação entre o fenômeno que ocorre e a sua observação, enquanto resposta macroscópica (Questão 2). Também foram positivas as respostas quanto às reações sugeridas como teste e sua cobertura em relação aos fenômenos usados na separação dos cátions (Questão 4) e a necessidade de estudo prévio da metodologia de separação dos cátions nos respectivos grupos (Questão 5). Curiosamente, houve uma diminuição na confiança de realizar os experimentos (Questão 3), provavelmente pela própria evolução no perfil dos alunos, ao enfrentarem processos reais ao invés de recorrerem a recursos virtuais, aos quais estão familiarizados.

Em relação à aceitação do método, nenhum aluno apresentou uma opinião contrária, como se pode observar na Figura 3, nas duas oportunidades avaliadas, sendo o aspecto de capacidade de observação o ponto de maior dificuldade levantado pelos discentes. Esse resultado é interessante, pois mesmo podendo trabalhar a capacidade de observação na disciplina de Química Analítica Qualitativa, os alunos 

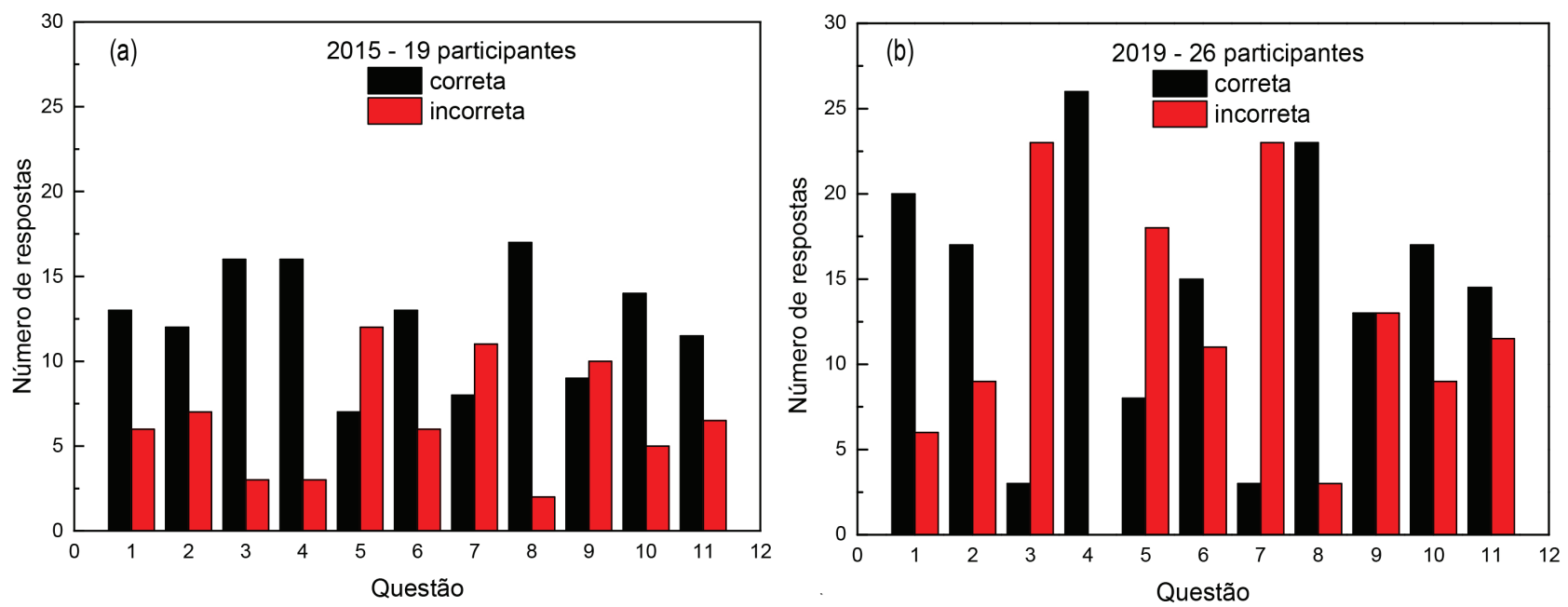

Figura 3. Respostas dos alunos ao questionário teórico (Figura 2S, Material Complementar) em (a) 2015 e (b) 2019

ainda assim ao final do semestre classificaram a observação como um ponto de significativa dificuldade.

Além disso, em decorrência do modelo abordado, foi constatado que houve uma redução do consumo de reagente, bem como a diminuição de 2/3 na geração de resíduos. Essa consequência já era esperada, pois as práticas foram realizadas em grupos, no entanto, com o modelo abordado, a redução foi ainda maior, pois as reações foram realizadas em tubos de ensaios, empregando-se pequenos volumes, com menor número de repetições.

Os resultados mostram que a realização das reações de identificação independente da separação facilitou o entendimento e o aprendizado dos conteúdos teóricos e práticos vivenciados em aula, sendo isso de suma importância, já que a química analítica clássica é um dos pilares da formação do bacharel em química.

Em nenhum dos casos houve resposta na questão (c).

Também foi realizada uma avaliação teórica, conforme teste de múltipla escolha apresentado no Figura S2 (apresentada como Material Suplementar). Esse questionário foi respondido ao final do curso, sem aviso prévio aos alunos e sem contar para a avaliação regular da disciplina, sendo o mesmo material aplicado às turmas de $2015 \mathrm{e}$ 2019. O teste foi respondido pelos alunos que aceitaram participar do processo, de forma voluntáira e anônima. A avaliação informal contou com dez questões conceituais, abordando características relevantes de cada grupo de cátions que foram estudados pelos alunos ao longo do semestre, cujos resultados são apresentados na Figura 3. O número de respostas corretas foi positivo, se comparado ao número de respostas erradas, mostrando nível de apropriação de conteúdo pelos alunos, que pode ser considerado satisfatório. De forma geral, os alunos tiveram mais dificuldades para responder às questões dos primeiros grupos de cátions estudados no laboratório, como os grupos I, IIB e IIIB. As dificuldades, representadas pelas respostas incorretas, não apresentaram alteração significativa entre as duas oportunidades em que a proposta foi avaliada, demonstrando nível de apropriação de conteúdo semelhante ao longo do tempo.

\section{Avaliação da proposta em questão livre}

Ao final da avaliação foi deixado um espaço aberto para comentários, críticas e sugestões sobre a metodologia e as impressões gerais sobre a disciplina. Destacam-se desses comentários, as seguintes observações, agrupadas pelo ano de aplicação.

Observações dos alunos da turma de 2015

$\mathrm{Na}$ primeira aplicação houve críticas ao material didático, que estava em fase de elaboração, tendo sido aperfeiçoado, com base nas críticas dos alunos:

"(sic)...Faltou mais "observações” sobre o que ocorre durante a realização da prática. Além disso, a falta de didática do material tornou-o razoável”.

"Alguns esquemas continham alguns erros de numeração ou reagentes, o que confundia, além disso, parte das reações não estavam no Vogel”.

No caso da aplicação da terceira etapa, houve dúvidas na separação dos grupos:

"As dificuldades se mostraram mais aparentes durante a separação dos grupos, (sic)...foi sanada porém com algumas dificuldades".

"A maior dificuldade se deu na separação do Grupo II em IIA e IIB".

Surgiram comentários sobre dificuldades normais de aprendizado do trabalho experimental, que puderam ser superados ao longo do curso:

“(sic)...A maior dificuldade foi o controle do pH para certas precipitações".

"O principal problema encontrado foi a aparição dos cátions em mais de um grupo, dificultando a análise dos demais. Porém, durante a análise das amostras as dúvidas foram sanadas".

"(sic)...E na transferência do resíduo do filtro para um bequer, sempre tenho dificuldade. E ainda não encontrei o arsênio".

"(sic)...A dificuldade de formar precipitados nos grupos IV e V foi sanada durante a aula após repetição da etapa”.

"...Essa dificuldade é facilmente sanada ao consultar o material didático, professor ou o técnico”.

Houve também apresentação de sugestões, associadas à dificuldade de entendimento da proposta, misturando as fases 1 e 2:

“...Além disso, seria interessante uma pergunta no fim da bateria de reação instigasse à elaboração de um próprio método de separação. Por exemplo, (sic)...após testar $\mathrm{CrO}_{4}^{2-}$ com todos do grupo $\mathrm{IV}$, o aluno poderia responder 
como separar $\mathrm{Ba}^{2+}$. Principalmente porque isto permite que, durante a separação o estudante se preocupe com outras coisas, como técnicas laboratoriais, em vez de pensar na reação que está ocorrendo".

Isso é exatamente o oposto da proposta, que visa forçar a observação dos fenômenos na primeira fase e aplicá-los na segunda fase. No material original há um questionário ao final de cada sequência de reações e as respostas podem ser apresentadas juntamente com o relatório da atividade.

Observações dos alunos da turma de 2019

Nota-se claro amadurecimento da proposta e da forma de aplicação pela equipe instrutora. Não há comentários sobre a qualidade ou problemas com o material didático, as tabelas de reações a serem estudadas. Nota-se também a mudança de pensamento dos estudantes e a influência do seu contato com o mundo digital em relação ao trabalho manual e repetitivo:

\section{"É um laboratório cansativo, às vezes perdia ofoco, mas fui} encontrando minha rotina".

Exemplos da aplicação da Química Analítica Qualitativa no cotidiano foram notados e considerados bem-vindos pelos discentes, como o caso clássico do contraste Celobar ${ }^{\circledR}$ em Goiânia/GO, 2003 $3^{29,30}$ e os acidentes de Mariana/MG (2015) ${ }^{31}$ e Brumadinho/MG (2019), ${ }^{32}$ com o rompimento das barragens de mineração.

"Sugestão: continuar relacionando a prática laboratorial com processos como o caso do celobar, achei muito interessante e me motivou bastante".

As dificuldades de aprendizado continuaram, como esperado, inerentes ao nível de formação dos alunos por ocasião do curso, além das dificuldades com a separação dos grupos de cátions (Etapa 3):

"A principal dificuldade foi acertar as quantidades de reagente para realizar as separações. (sic)...A maioria das dúvidas foram sanadas pelo professor".

"A dificuldade encontrada durante a análise da amostra foi em separar os grupos em a perda de analitos durante o processo, mas com auxílio do professor consegui encontrar os erros realizados durante o processo".

A importância de uma equipe instrutora comprometida com a disciplina se mostra fundamental, nesses comentários.

\section{CONCLUSÕES}

Uma nova abordagem da disciplina, em um conceito construtivista, foi proposta e aplicada para ensino de Laboratório de Química Analítica Qualitativa. A proposta baseia-se em uma série de reações específicas para cada grupo de cátions, seguida da pesquisa dos fenômenos envolvidos por parte dos alunos. Segue-se uma etapa de esclarecimento das aplicações dessas reações na separação dos cátions intragrupos, com base nas reações estudadas na etapa anterior.

A proposta foi desenvolvida considerando-se o tempo reduzido de aula e a importância da disciplina para o aprendizado de conteúdos básicos nos cursos de química.

A proposta passou por uma evolução no período de quatro anos, aqui relatados. Pode-se considerar que foi bem aceita e resultou em apropriação de conteúdo por parte dos discentes, conforme respostas aos questionários avaliativos. Além disso, houve redução de 2/3 no volume de resíduos gerados em relação ao uso da tradicional marcha analítica.

\section{MATERIAL SUPLEMENTAR}

Os questionários avaliativos e de opinião estão disponíveis em http://quimicanova.sbq.org.br, em formato PDF, com acesso livre.

\section{AGRADECIMENTOS}

Às agências CNPq e CAPES (Finance Code 001)e, em especial, à Sra. Renata Meire dos Santos e ao Sr. Glauco Dimas Broch, técnicos do laboratório de ensino do IQSC/USP pelas críticas, sugestões e apoio no desenvolvimento da proposta, desde as primeiras tentativas.

\section{REFERÊNCIAS}

1. http://portal.mec.gov.br/seesp/arquivos/pdf/lei9394_ldbn1.pdf, acessada em novembro 2020.

2. Calefi, R. M.; Dissertação de Mestrado, Universidade de São Paulo, Instituto de Química de São Carlos, Brasil, 2010.

3. Christian, G. D.; Analytical chemistry, $5^{\text {th }}$ ed., Willey \& Sons: New York, 1994.

4. Skoog, D. A.; Holler, F. J.; Princípios de análise instrumental, 5a ed., Bookman: Porto Alegre, 2002

5. Alvim, T. R.; Andrade. J. C.; Quim. Nova 2006, 29, 168.

6. Whiten, K. W.; Davis, R. E.; Peck, M. L.; General chemistry with qualitative analysis, $5^{\text {th }}$ ed., Saunders College Publishing: Fort Worth, 1996.

7. Strong III, F. C.; J. Chem. Educ. 1957, 34, 400.

8. Freiser, H.; J. Chem. Educ. 1957, 34, 387.

9. Baum, R. M.; Chem. Eng. News 1984, 62, 31.

10. Benedetti-Pichler, A. A.; Schneider, F.; Steinbach, O. F.; J. Chem. Educ. 1957, 34, 381.

11. Frank, R. E.; J. Chem. Educ. 1957, 34, 383.

12. https://jornal.usp.br/institucional/pro-reitoria-de-pos-graduacao-criacatedra-paschoal-senise, acessada em novembro 2020.

13. http://www.abc.org.br/membro/paschoal-ernesto-americo-senise, acessada em novembro 2020

14. Senise, P. E. A.; Quim. Nova 1982, 5, 137.

15. Kolthoff, I. M.; Anal. Chem. 1973, 45, 24A

16. Laitinen, H. A.; Anal. Chem. 1980, 52, 605A.

17. Senise, P. E. A.; Quim. Nova 1983, 6, 112.

18. Kryger, L.; Talanta 1981, $28,871$.

19. Baccan, N.; Godinho, O. E. S.; Aleixo, L. M.; Stein, E.; Introdução à semicroanálise qualitativa, $7^{\mathrm{a}}$ ed., Editora da UNICAMP: Campinas, 1997.

20. http://www.prpg.usp.br/pt-br/pae/o-que-pae, acessada em novembro 2020.

21. https://www.crq4.org.br/o_que_faz_um_quimico, acessada em novembro 2020.

22. https://g1.globo.com/sp/sorocaba-jundiai/noticia/2019/12/11/area-ondefuncionava-empresa-saturnia-e-arrematada-por-r-29-milhoes-em-leilao. ghtml, acessada em novembro 2020.

23. Vogel, A. I.; Química Analítica Qualitativa, 5ª ed., Mestre Jou: São Paulo, 1981.

24. Brumblay, R.; Qualitative Analysis, $3^{\text {rd }}$ ed., Barnes \& Noble: New York, 1964.

25. Ausubel, D. P.; The Psychology of Meaningful Verbal Learning, Grune \& Stratton: London, 1963.

26 Construtivismo e ensino de ciências: reflexões epistemológicas e metodológicas; Moraes, R., org.; EDIPUCRS: Porto Alegre, 2000.

27. http://www.ccsc.usp.br/residuos, acessada em novembro 2020. 
28. https://uspdigital.usp.br/jupiterweb/obterDisciplina?sgldis=sqm0408\& nomdis=, acessada em novembro 2020.

29. https://www1.folha.uol.com.br/fsp/opiniao/fz1106200303.htm, acessada em novembro 2020

30. https://portal.cfm.org.br/index.php?option=com_content\&view=article $\& \mathrm{id}=2467: \&$ catid=, acessada em novembro 2020.
31. https://www1.folha.uol.com.br/cotidiano/2015/11/1706510-tragedia-emminas-gerais-deve-secar-rios-e-criar-deserto-de-lama.shtml, acessada em novembro 2020.

32. https://tudo-sobre.estadao.com.br/brumadinho-mg, acessada em novembro 2020 . 